\title{
NOTE
}

\section{Collecting a sample of loggerhead sea turtle hatchlings before a natural emergence does not reduce nest productivity}

\author{
Michael Salmon ${ }^{1, *}$, Raymond R. Carthy ${ }^{2}$, Catherine M. F. Lohmann ${ }^{3}$, \\ Kenneth J. Lohmann ${ }^{3}$, Jeanette Wyneken ${ }^{1, * *}$ \\ ${ }^{1}$ Department of Biological Sciences, Florida Atlantic University, Boca Raton, Florida 33431, USA \\ ${ }^{2}$ US Geological Survey, Florida Cooperative Fish and Wildlife Research Unit, Gainesville, Florida 32611, USA \\ ${ }^{3}$ Biology Department, University of North Carolina, Chapel Hill, North Carolina 27599, USA
}

\begin{abstract}
In numerous studies involving hatchling sea turtles, researchers have collected small numbers of hatchlings from nests a few hours before the turtles would otherwise have emerged naturally. This procedure makes it possible to do experiments in which the behavioral or physiological responses of numerous hatchlings must be tested in a limited period of time, and also allows hatchlings to be released back into the sea in time to migrate offshore before dawn. In principle, however, the procedure might inadvertently reduce nest productivity (the number of hatchlings that successfully leave the nest), if digging into a nest prior to emergence somehow reduces the ability of the remaining turtles to emerge. We compared nest productivity in 67 experimental loggerhead nests, from which we removed 10 hatchlings before a natural emergence, to 95 control nests left undisturbed before a natural emergence. The 2 groups showed no statistical differences in productivity. We conclude that taking a few hatchlings from a loggerhead nest shortly before a natural emergence has no negative impact on hatchling production if sampling is done with care at locations where there are few nest predators, and at sites where an emergence can be predicted because nest deposition dates are known.
\end{abstract}

KEY WORDS: Loggerhead turtle $\cdot$ Nests $\cdot$ Hatchlings $\cdot$ Emergence $\cdot$ Permits $\cdot$ Conservation

Resale or republication not permitted without written consent of the publisher

\section{INTRODUCTION}

Sea turtle hatchlings emerge from nests buried on oceanic beaches, crawl to the surf zone and swim rapidly offshore. The orientation of these movements depends upon the detection of certain external cues ('guideposts') that the turtles are primed to perceive during this stage of their development. The result is a kind of specialized behavior, characteristic of most animals during migration (Dingle 1996). That behavior makes hatchlings ideal subjects for studies of orientation and navigation, as well as of the way certain anthropogenic perturbations (such as artificial lighting) affect the fate of the hatchlings that depart from nests placed on those beaches.

In Florida, USA, we study these as well as other aspects of marine turtle behavior. Our subjects are usually the most abundant of the marine turtle hatchlings (loggerheads Caretta caretta) but the turtles are only available for a few weeks during the summer (mid-July through late August). Those seasonal constraints limit the amount of data that can be collected through experimentation each year. There are also diel constraints. In Florida, loggerhead hatchlings 
emerge from nests most often between 22:00 and 02:00 h (Witherington et al. 1990). This leaves investigators with little time to capture their subjects, expose them to an experimental protocol and then return them to the beach for release within this presumed optimal time window.

For a number of years, we have dealt with these problems by removing a few hatchlings each day from several nests, generally in the afternoon prior to natural nocturnal emergences. We target nests that have been incubating long enough for the hatchlings to have left the confines of their eggs. We usually find the turtles resting as a group just above the mass of empty eggshells or, if they have commenced upward digging, within a few centimeters of the beach surface. We collect a few of these turtles, leaving the rest of the clutch undisturbed to emerge on their own that evening.

The turtles we take are stored in small coolers containing moist sand from the nest interior. The coolers are kept in a dark room at shaded temperatures. Under these conditions, the hatchlings remain inactive until we stimulate them through exposure to cooler (air-conditioned) laboratory temperatures. An analogous process activates the turtles within the nest as the hot beach sands that inhibit locomotion become cooler after sunset and the turtles begin to dig their way out of the nest (Mrosovsky 1968, Gyuris 1993, Moran et al. 1999, Glen et al. 2005). By inducing the captured turtles to become active earlier in the dark cycle, we have sufficient time to complete our experiments, return the turtles to the beach, and release them when many other hatchlings, emerging naturally, begin their migration.

These procedures appear to satisfy the requirements of scientists, and hatchlings collected in this way seem healthy and vigorous. There has, however, been concern expressed that hatchlings remaining in the nest might be adversely affected by the intrusion into their nest. The Florida Fish and Wildlife Conservation Commission (FWC) was specifically concerned that digging into the nest might in some way reduce nest productivity (the number of hatchlings that left the nest and were presumed to enter the sea). To determine if such an impact occurred, we undertook a comparison of nest productivity between nests from which a few hatchlings had been removed and nests that were left intact and undisturbed.

\section{MATERIALS AND METHODS}

Loggerhead nests were surveyed during the summer of 2010 along a $4.5 \mathrm{~km}$ long section of beach in Boca Raton (Palm Beach County), Florida $\left(26^{\circ} 22^{\prime} \mathrm{N}\right.$, $80^{\circ} 07^{\prime} \mathrm{W}$; Fig. 1). This nesting beach is managed by staff from the Gumbo Limbo Nature Center. Each day, nests deposited the previous night were marked with stakes and signage, numbered, and located by GPS coordinates. In a few areas, nests were screened to thwart predators (foxes, skunks and raccoons). The nests used in this study were a subset of those deposited on the beach between 5 May and 19 August.

To accommodate our experiments, some of these nests were assigned to our control (undisturbed) group and experimental (nests from which a few hatchlings were removed) group. The experiment

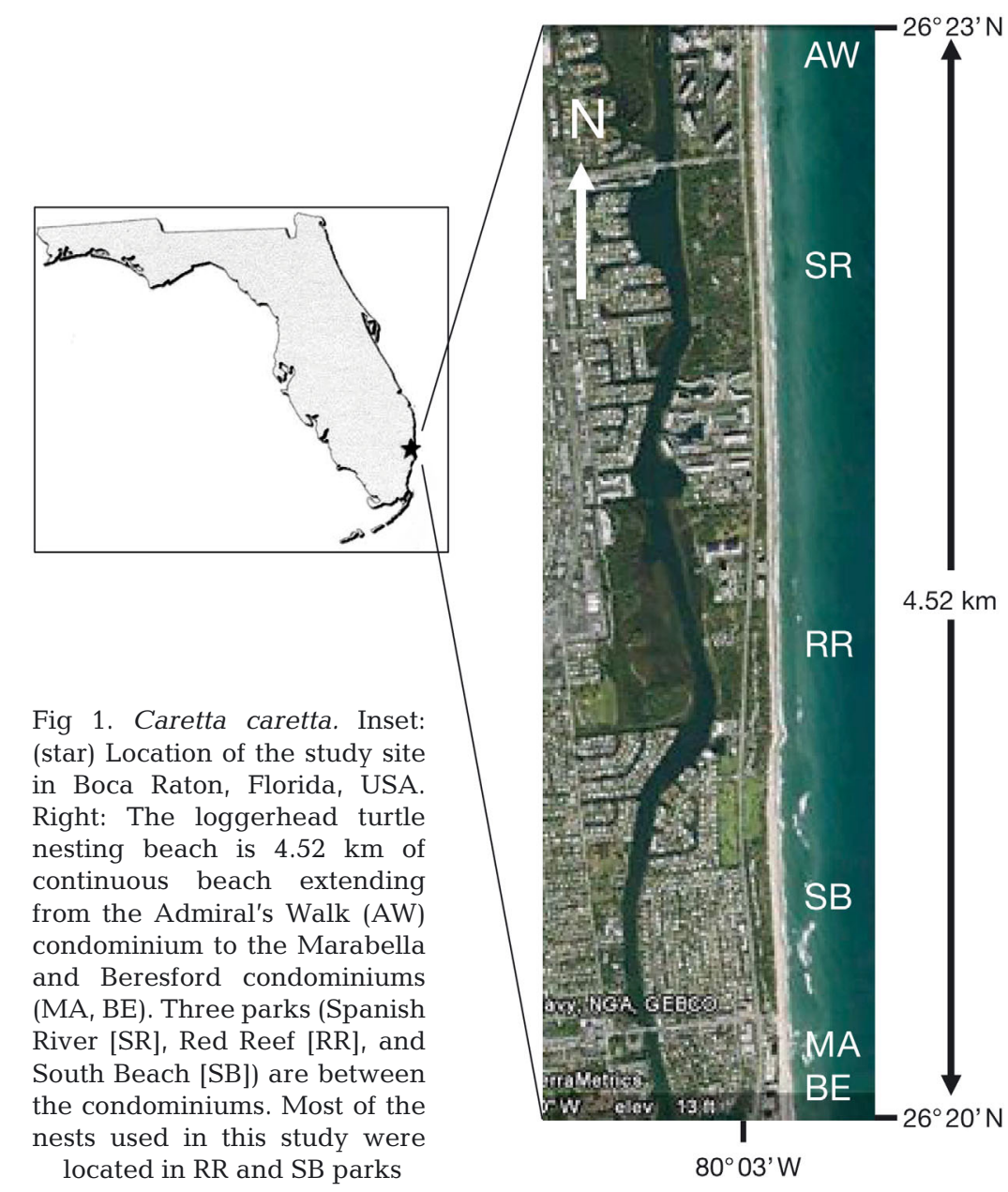


was designed in collaboration with Blair Witherington (FWC) who used power analyses of past records from loggerhead nests in Florida to estimate a statistically reliable sample size (minimum 62 experimental and 62 control nests) for the study.

Most of the nests were located in front of the city parks (Fig. 2), favored because of ample parking close to the beach and walkways between the parking lot and beach that allowed for convenient access to any nests targeted each day for inspection. All nests were located sufficiently far above mean high tide to minimize the risk of inundation or 'wash-out' by a storm-induced tide. None of the nests in our data set were relocated.

Gumbo Limbo staff excavated each nest within $3 \mathrm{~d}$ after an emergence (as determined by hatchling tracks leading from the nest to the ocean) or by Day 70 post deposition (if no tracks were seen). Exca-

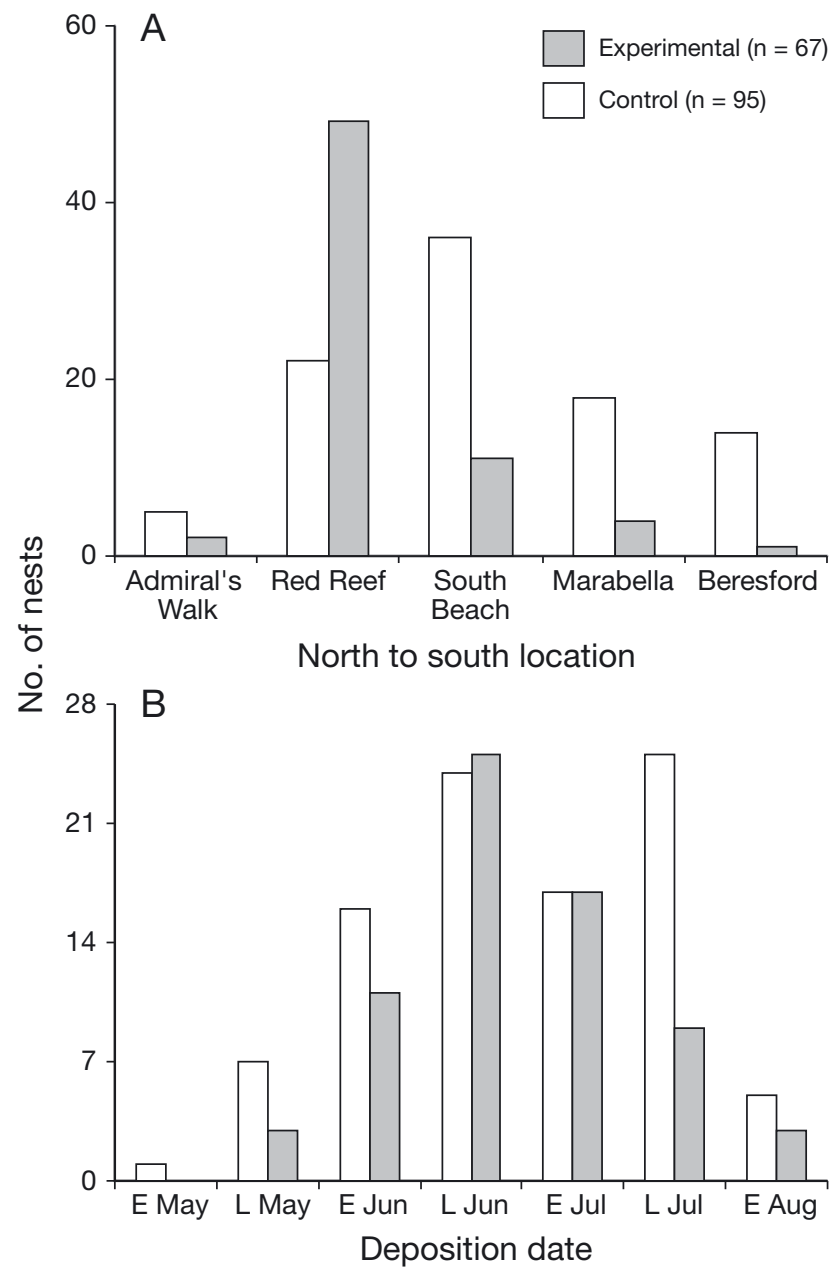

Fig 2. Caretta caretta. (A) Spatial distribution of the experimental and control nests (see Fig. 1 for locations). (B) Temporal distribution (deposition by month) of the nests. E: first half of the month; L: last half of the month vations were done to determine clutch size (the number of unhatched eggs plus the number of broken egg shells) and the number of hatchlings (alive or dead) that remained within the nest after the competent hatchlings departed. The number of broken egg shells, minus the number of hatchlings remaining in the nest, yields the number of hatchlings that departed from the nest (nest productivity). At the time of inventory, staff did not know which nests were in the control group and which were in the experimental group.

The number of incubation days from other nearby nests was used to estimate the expected emergence date for experimental nests. Hatchlings were collected from experimental nests in the late afternoon $1 \mathrm{~d}$ in advance of the expected emergence date. To assure uniformity only one of us (M.S.) dug into the nests. In the past, we typically collected 10 hatchlings from each nest, and we followed the same procedure in this study. If fewer than 10 hatchlings were present in either an experimental or control nest, that nest was not included in the analysis.

Control and experimental nests were compared with respect to 3 variables: clutch size, nest productivity, and incubation days before an emergence. Distributions for clutch size and nest productivity were either normal or nearly so, and showed similar variances. These comparisons were made using $t$-tests. Incubation duration, however, was skewed and so comparisons between experimental and control nests were made using a Mann-Whitney 2-sample $U$-test. All differences were considered statistically significant when $\mathrm{p} \leq 0.05$.

\section{RESULTS AND DISCUSSION}

By the end of the field season our data set consisted of 67 experimental and 95 control nests, none of which were attacked by predators. The majority of the nests were located within a $2 \mathrm{~km}$ section of continuous beach in Red Reef and South Beach parks (Fig. 2A). The temporal distribution of these nests reflected the usual seasonal pattern of loggerhead nesting in southeast Florida (nesting reaches a peak during the months of June and July; Fig. 2B). Hatchlings in the experimental nests were most often found well below (up to $\sim 30 \mathrm{~cm}$ ) the beach surface, and on top of empty egg shells and unhatched eggs.

There were no statistical differences in clutch size or in nest productivity between the control and experimental nests (Table 1). However, incubation duration was shorter by about $1 \mathrm{~d}$ (mode of $48 \mathrm{~d}$ ) in the 
Table 1. Caretta caretta. Clutch size (no. of unhatched eggs plus no. of broken egg shells) and emerged hatchlings were compared for the experimental and control nests using $t$-tests: data are presented as mean $\pm \mathrm{SD}$ and range (in parentheses) for each group. Data for incubation duration were not normally distributed and are given as mode and range (in parentheses). Statistical comparisons were made using non-parametric (Mann-Whitney $U$-test) statistics

\begin{tabular}{|lcc|}
\hline Parameter & Experimental & Control \\
\hline Clutch size & $99.8 \pm 21.7$ & $96.2 \pm 26.7$ \\
& $(57-182)$ & $(10-117)$ \\
$t=0.95, \mathrm{p}=0.3$ \\
Emerged hatchlings & $53.4 \pm 22.3$ & $54.1 \pm 26.9$ \\
& $(10-102)$ & $(11-117)$ \\
& $t=0.16, \mathrm{p}=0.8$ \\
Incubation duration (d) & 48 & 49 \\
& $(46-53)$ & $(44-53)$ \\
& \multicolumn{2}{c}{$z=2.6, \mathrm{p}<0.01$} \\
\hline
\end{tabular}

experimental compared to the control nests (mode of $49 \mathrm{~d}$, Table 1; Mann-Whitney $z=2.6, \mathrm{p}<0.01$ ).

On the basis of these data, we conclude that digging into a loggerhead nest to remove a few hatchlings has no statistically significant effect on nest productivity. These results appear to be robust in that the present study used natural in situ nests and produced the same findings as an older study that used hatchery nests. In the older study, one of us (J.W.) used nests relocated to a Broward County, Florida, on-the-beach hatchery in the 1990s. Hatchlings were removed from about 40 nests and subsequent productivity of those nests was compared to undisturbed hatchery nests. The 2 groups showed no statistical differences in productivity. A summary report was submitted to the Florida Department of Natural Resources, but both the report and data have now been misplaced.

In our current study, the only statistical difference between the control and experimental nests was in incubation duration, shorter by about $1 \mathrm{~d}$ in the experimental nests. Determining why this occurred was beyond the scope of our study. Unusual climatic conditions in the summer of 2010 (high temperatures, low rainfall; Bosley et al. in press) may have been responsible for the presence of a hard crust of salty sand, up to several centimeters in thickness above the egg chamber in some of the nests. The process of removing hatchlings may have softened the sand above the experimental nests and facilitated the egress of the remaining hatchlings. Indeed, it is possible that these hatchlings used less energy to escape the nest and thus began their migration with greater available energy reserves.
In summary, the removal of a small number of loggerhead hatchlings from natural nests may be a useful procedure when scientists need more time to obtain measurements or to complete experiments. Doing so also allows scientists to complete their task and then release the hatchlings during what appears to be an optimal time window for the turtles. While we show here that the take of pre-emergent hatchlings has no apparent effect on nest productivity, it is nevertheless an intrusive procedure that must be executed with care. Only a few hatchlings should be taken, leaving the bulk of the clutch in place to socially facilitate one another's digging toward the beach surface (see review by Lohmann et al. 1997). It is especially important to minimize disturbing the hatchlings that are left behind so that they remain quiescent. Early hatchling removal is best performed where nests are marked and monitored on a daily basis, where natural predation rates are low, and where the predators that remain are unlikely to be attracted to disturbed sites by visual or odor cues (Stancyk 1982). We emphasize that even if early hatchling removal is advantageous for research, scientists and their students must learn where, when and how that removal should be done.

Acknowledgements. This study would not have been possible without the City of Boca Raton's support of the Beach Monitoring Sea Turtle Program at the Gumbo Limbo Environmental Complex. We are especially grateful to Kirt Rusenko and Cody Mott for their cooperation and assistance, and to the entire 2010 Gumbo Limbo Sea Turtle Specialist crew (Rick Newman, Mike Anderson, Juan Duarte, Trevor Tyner and Heather Iannozzi) for excavating nests. Morgan Young returned the hatchlings to the beach each night and released them. We thank Blair Witherington (FWC) for his assistance in the experimental design, and Tim O'Meara and Tim Breault (FWC) for convincing their colleagues at the Imperiled Species Management Division (which permits marine turtle research in Florida) that this study should be done. Permit approval soon followed (FWC Turtle Permit 173).

\section{LITERATURE CITED}

Bosley JW, Rogers MM, Anderson ZD, Mott CR, Wyneken J (in press) Record high beach temperatures: implications for sea turtle emergence success in Boca Raton. Poster presentation, 31st Ann Symp on Sea Turtle Biology and Conservation, April 2011, San Diego, CA. US Department of Commerce, Miami, FL

Dingle H (1996) Migration: the biology of life on the move. Oxford University Press, Oxford

Glen F, Broderick AC, Godley BJ, Hays GC (2005) Patterns in the emergence of green (Chelonia mydas) and loggerhead (Caretta caretta) turtle hatchlings from their nests. Mar Biol 146:1039-1049 
Gyuris E (1993) Factors that control the emergence of green turtle hatchlings from the nest. Wildl Res 20:345-353

Lohmann KJ, Witherington BE, Lohmann CMF, Salmon M (1997) Orientation, navigation and natal beach homing in sea turtles. In: Lutz P, Musick JA (eds) Biology of sea turtles. CRC press, Boca Raton, FL, p 107-135

Moran KL, Bjorndal KA, Bolten AB (1999) Effects of the thermal environment on the temporal pattern of emergence of hatchling loggerhead turtles Caretta caretta. Mar Ecol Prog Ser 189:251-261

Editorial responsibility: Matthew Godfrey, Beaufort, North Carolina, USA
Mrosovsky N (1968) Nocturnal emergence of sea turtles: control by thermal inhibition of activity. Nature 220: 1338-1339

Stancyk SE (1982) Non-human predators of sea turtles and their control. In: Bjorndal KA (ed) Biology and conservation of sea turtles. Smithsonian Institution Press, Washington, DC, p 139-152

- Witherington BE, Bjorndal KA, McCabe CM (1990) Temporal pattern of nocturnal emergence of loggerhead turtle hatchlings from natural nests. Copeia 1990:1165-1168

Submitted: September 13, 2011; Accepted: December 10, 2011 Proofs received from author(s): March 3, 2012 